immortality stems from an article he published in 1832 in the Journal of the Medical and Chirurgical Society entitled 'On some morbid appearances of the absorbent glands and spleen'. He described the gross pathological changes in 6 cases he had encountered at Guy's during his time as Curator of the Museum (1825-1837). This was a macroscopic description, for his microscope was a primitive combination of lenses developed by a London wine merchant, J. J. Lister (father of Sir Joseph Lister). In 1926 the pathological material from the 6 patients whom Hodgkin had described in 1832 were subjected to modern histology. Hodgkin's disease was confirmed in 3 , one had tuberculosis, another had syphilis, and a non-Hodgkin's lymphoma in the other. His other claim to fame as a doctor was that he introduced Laennec's stethoscope to London medical circles. Whilst still a medical student at Edinburgh, he went to Paris in 1821 for an overseas elective which lasted one year. He attended Laennec's lectures at Necker Hospital, and soon after his return to London he presented a paper on Laennec's stethoscope to Guy's Hospital Physical Society in October 1822.

Michael Rose, author of this delightful biography of Hodgkin, is a London haematologist and a Guy's man. He guides us through the medico-political intrigues behind Hodgkin's failure to become a consultant physician at Guy's in 1837, when his medical career came to an abrupt end. Following this setback he devoted his life to social reform. Dr Rose persuades the reader convincingly that Hodgkin's tragedy, perhaps, was that his standards in medicine and on issues of human rights were always in advance of his time.

When he was aged 51 years, Hodgkin married a widow with 2 grown-up sons, but he had no children of his own. His brother, John, had 12 children so we are fortunate to have several distinguished Hodgkins today.

This book is so enjoyable that you will not be able to put it down until you have finished it. The author maintains our interest throughout because he has researched his background data painstakingly and has a most polished, elegant style of authorship.

\section{Drug Reactions and the Liver}

Edited by Michael Davis, J. Michael Tredger and Roger Williams. Pp. xii +364 , illustrated. Pitman Medical, London, 1981. £20.00.

Adverse effects upon the liver are among the most important of drug reactions, and many of them are fatal, despite our better understanding of their nature and increasingly sophisticated methods of management. This volume, edited by the staff of the King's College Hospital Liver Unit, is the record of a symposium held in 1980 to review the pathogenesis and treatment of a variety of drug-induced liver disorders, including those due to paracetamol, halothane and oral contraceptives. Its production is excellent, and a particularly valuable feature is the edited record of the discussions that took place, showing that there is still uncertainty over many issues which some of us thought were resolved long ago! This book represents a major milestone in clinical toxicology and should be readily available to all involved in clinical research.

\section{The Endometrium}

By W. B. Robertson. Pp. xii +201 , illustrated. Butterworths, London, Boston, 1981. £25.00.

This book is a volume of the publisher's Postgraduate Pathology Series and as such will have most immediate appeal to histopathologists who are required to deal with gynaecological specimens. However, Professor Robertson has succeeded in dealing with his subject in a very clinical way so that the result is also of great potential interest and benefit to the practising gynaecologist.

Following some introductory remarks the book deals with the appearances to be seen in normal endometrium and then with the detailed microscopical changes found in association with various abnormalities of the menstrual cycle. Chapter four discusses the changes of pregnancy, both normal and abnormal, and there follows detailed description of the changes of endometritis and of iatrogenic effects. The book ends with consideration of the features of neoplastic diseases of the endometrium.

Professor Robertson's writing is both interesting and informative as well as occasionally amusing and the excellent text is well illustrated with 213 photomicrographs. All the illustrations are in black-and-white but this seems to be no disadvantage since they are well chosen to illustrate the point under discussion. No references are provided within the text which will be a handicap to anyone wishing to pursue individual points but each chaper ends with a selected list for further reading and the author adds his own brief comment on each suggested item. There is a good index.

This is a book which should certainly find a useful place on the microscope bench of any gynaecological histopathologist but it would also be of interest and value to most clinical gynaecologists both in improving the quality of information provided with requests for examination of specimens and by helping to elucidate the implications of the resulting reports. It is unfortunate that the price, presumably the result of the necessarily large number of photographic blocks, may deter some potential purchasers.

\section{A Handbook of Obstetrics and Gynaecology for the House Officer}

By Mary M. Anderson. Pp. 174. Faber and Faber, London, 1981. £3.95.

This book is intended to be carried in the pocket of the new houseman in obstetrics or gynaecology to provide him with a source of instant advice on the various problems which may confront him in his day-to-day work. As such it makes no attempt to provide more than the basic practical requirements and those requiring further information will need to refer to the standard textbooks on the subjects.

The practical aspects of work in the antenatal clinic and ward, the labour ward and the postnatal ward and the clinic are each dealt with in turn and the obstetric section ends with a useful chapter on the assessment and management of the neonate. The gynaecological section also deals with clinic and ward work and then goes on to advise about gynaecological emergencies and certain practical procedures and includes short sections on contraception and on the social and legel aspects.

In any book of this sort there will always be occasional subjects which some would omit and others would include but I was surprised to find no mention of termination of pregnancy by prostaglandins, a procedure which many housemen may need to know. I should also like to have seen rather more discussion of alternative forms of contraception so that the houseman is properly equipped to discuss the various pros and cons with his patients (all the 'recommended' methods are well covered but there is no mention, for example, of coitus interruptus.)

This book succeeds in remaining suffiziently general in its advice to be readily adaptable to the routines in most units and it should provide useful guidance as to the procedure to be followed in situations where the new resident may yet need to have practical advice from his more senior colleagues. 